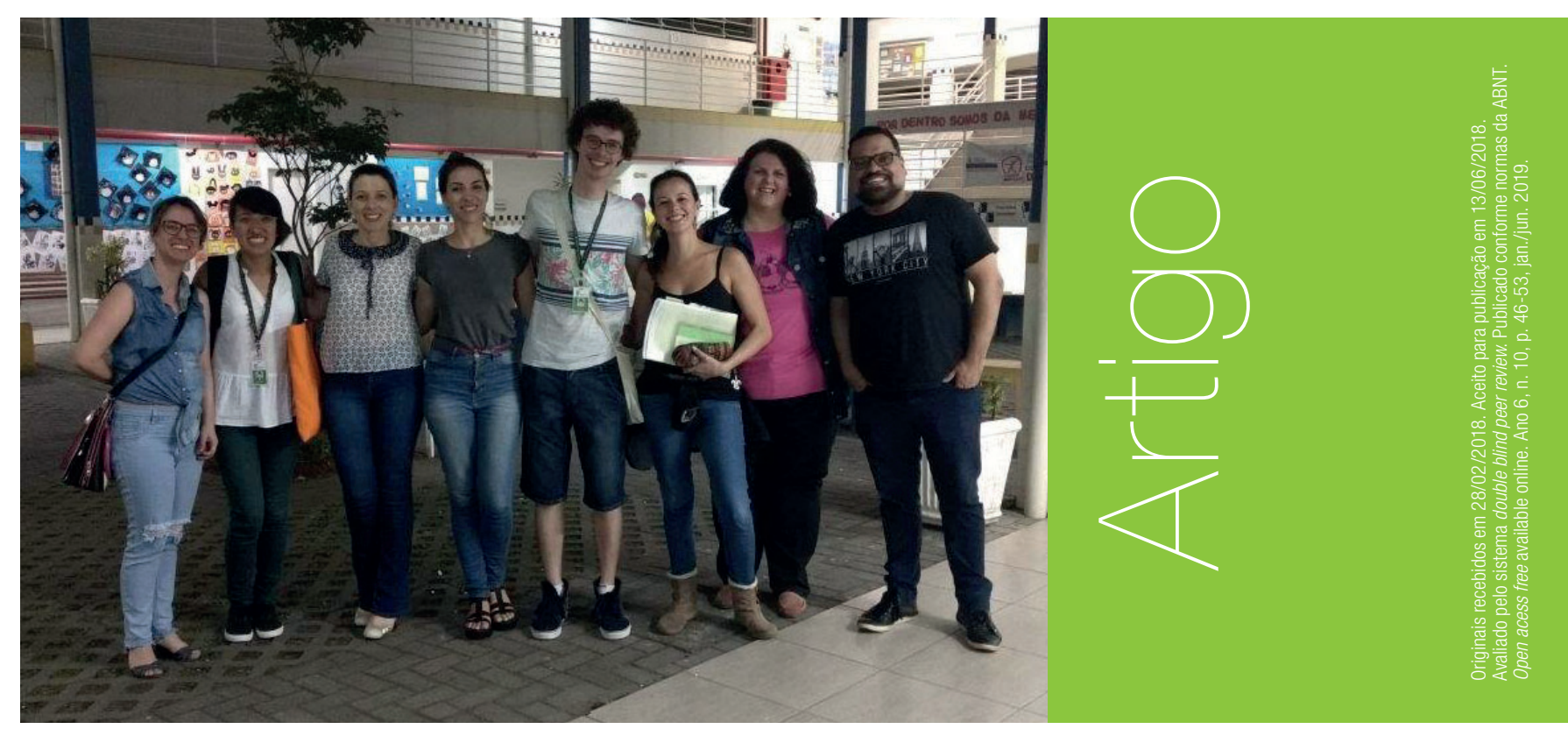

\title{
"Olhos D'Água": promovendo o estímulo à leitura e a igualdade de gênero em escolas da rede pública de Itajaí
}

\author{
Eliane Pellegrini - eliane.pellegrini@ifsc.edu.br ${ }^{1}$ \\ Leonardo da Silva - leonardo.silva@ifsc.edu.br ${ }^{2}$ \\ Beatrice Gonçalves - beatrice.goncalves@ifsc.edu.br ${ }^{3}$ \\ Melina Chiba Galvão - melina.chiba@ifsc.edu.br ${ }^{4}$
}

\section{RESUMO}

0 projeto de extensão "Olhos D'Água": promovendo o estímulo à leitura e à igualdade de gênero em escolas da rede pública de Itajaí teve como objetivo promover reflexões sobre gênero e incentivar a formação de leitores tendo como público-alvo alunos e servidores de escolas da rede municipal de ensino que ofertam cursos voltados para a Educação de Jovens e Adultos (EJA). Dentre as atividades desenvolvidas, estiveram oficina de formação em leitura dramática, roda de conversa com professores sobre a temática gênero bem como leituras dramáticas com alunos e professores nas escolas. 0 projeto, desenvolvido no último trimestre de 2017, objetivou contribuir para 0 estímulo à reflexão e discussão sobre as questões de gênero no ambiente escolar e sobre o papel de alunos e professores na construção de uma sociedade igualitária.

\footnotetext{
1 Mestra em Ciência da Informação (UFSC) e Bibliotecária do IFSC - Câmpus Itajaí.

2 Mestre em Inglês: Estudos Linguísticos e Literários (UFSC) e Professor do IFSC - Câmpus Itajaí

3 Mestra em Antropologia Social (UFSC) e Jornalista do IFSC - Câmpus Itajaí.

4 Mestra em Educação Ambiental (FURG) e Professora do IFSC - Câmpus Itajaí.
} 


\section{PALAVRAS-CHAVE}

Leituras dramáticas. Igualdade de Gênero. Educação de Jovens e Adultos.

\section{ABSTRACT}

The extension project entitled "Olhos D'Água": promoting reading and gender equality in public schools in Itajai aimed at promoting reflections on gender as well as encouraging the act of reading among students, teachers and staff in the public system of education for Youth and Adults. The implemented activities included a workshop on dramatic readings, a discussion group on gender for teachers, and also dramatic readings with students and teachers in different schools. The project, which took place in the last quarter of 2017, had as its objective to encourage the process of reflection and discussion regarding gender issues in the school context and the role of students and teachers in the construction of an egalitarian society.

\section{KEYWORDS}

Dramatic readings. Gender Equality. Youth and Adult Education.

\section{Introdução}

Tanto a escola quanto o mundo do trabalho constituem espaços que instituem normas acerca de gênero e sexualidade (LOURO, 2008), podendo então contribuir para a polarização de gênero. Desta forma, é papel da escola "fazer com que alunos e alunas reflitam (...), desconstruindo preconceitos de gênero e contribuindo para a construção de novos modelos de relação entre homens e mulheres pautados em princípios de justiça e igualdade" (PUP0, 2007, p. 7). Dentro dessa perspectiva, entende-se que trabalhar questões de gênero em sala de aula nos permite analisar relações sociais e de poder. Gênero, neste contexto, é uma categoria de análise.

Para promover o desenvolvimento da criticidade acerca das relações de gênero, partiu-se da premissa de que a Pedagogia Crítica (CROOKES, 2013) pode servir como um lócus para 0 desenvolvimento de cidadãos críticos e conscientes, uma vez que esta consiste no ensino voltado à justiça social, de forma a apoiar o desenvolvimento de cidadãos ativos e engajados. Para que isso ocorra, é importante que os alunos (e professores, no caso deste projeto) não sejam meros receptores de informação, mas que possam atuar como verdadeiros pesquisadores de questões relevantes para os seus contextos.

Do ponto de vista da Pedagogia Crítica, todos participam do processo de seleção de conteúdos e materiais para oficinas e leituras e os professores (neste caso, os mediadores) atuam como mediador do processo de ensino-aprendizagem, ressignificando a hierarquia da sala de aula tradicional. Daí a importância do formato oficina ou roda de conversa. Faz-se necessário, dessa forma, que os participantes tenham um papel ativo na construção do conhecimento, que temas de relevância social (como a questão de gênero) sejam os norteadores do processo de ensinoaprendizagem e que o diálogo seja a base do desenvolvimento crítico.

A escolha da obra Olhos D'Água da escritora e professora mineira Conceição Evaristo está diretamente vinculada aos objetivos do projeto, que tem como pano de fundo teórico e metodológico a Pedagogia Crítica e as questões de gênero. 0 livro foi ganhador do prêmio Jabuti de 2015 e é formado por um conjunto de 15 contos centrados, em sua maioria, em personagens femininas, cuja temática está relacionada às agruras diárias pelas quais passam os negros e negras em uma sociedade excludente como a nossa. A interseccionalidade do contexto de vida da autora amplia o enfoque de discussões para além de questões de gênero, incluindo questões étnicas, sociais e de igualdade racial (LIMA, 2016).

A opção por um livro escrito por uma mulher negra se dá em um contexto em que o próprio mercado editorial brasileiro se configura enquanto um espaço de poder majoritariamente 
masculino. Segundo a autora Regina Dalcastagné (2012) no livro "Literatura brasileira contemporânea: um território contestado", $72 \%$ dos autores publicados no Brasil pelas três maiores editoras brasileiras (Letras, Rocco e Record) entre 1990 e 2004 são homens brancos, de classe média, moradores do Rio de Janeiro e São Paulo. Ainda, segundo a pesquisa, a maior parte dos protagonistas dos livros de literatura são homens, sendo que as mulheres aparecem em sua maioria como personagens marginais como, por exemplo, donas de casa.

Para estimular a leitura e a aproximação dos professores participantes com a obra, optou-se por usar o recurso da leitura literária dramática, também conceituada como leitura vocalizada ou leitura performática. Ela é entendida como uma forma de incorporar a experiência da leitura sob a experimentação da literatura no próprio corpo. Segundo Oliveira (2010), tal experimentação no corpo ocorre, mais especificamente, na voz, ou seja,

quando a voz do leitor reverbera 0 texto, ele adensa aquelas palavras (antes presas ao papel ou à tela ou a outro suporte), tornando-as vibração. Elas ganham então uma nova circulação sanguínea e espacial, penetram no leitor, deixando rastros; e o leitor, por sua vez, ao ressoá-las, confere às palavras novas colorações (OLIVEIRA, 2010, p. 285).

A leitura dramática serviu como instrumento para a promoção da leitura e da discussão sobre gênero, e foi oportunizada através da parceria com outro projeto de extensão desenvolvido no câmpus Joinville.

\section{Justificativa}

0 desenvolvimento do projeto de extensão intitulado "Olhos D'Água": promovendo o estímulo à leitura e à igualdade de gênero em escolas da rede pública de Itajaí justificou-se por diversos fatores. Primeiramente, pode-se observar na contemporaneidade a urgência de desenvolver políticas e ações voltadas para as questões de gênero. Em 2015, governo, países e sociedade civil tiveram a oportunidade de adotar uma nova agenda de desenvolvimento sustentável a ser atingida até 2030, com 17 Objetivos de Desenvolvimento Sustentável (ODS), que se baseiam nos oito Objetivos de Desenvolvimento do Milênio (ODM). 0 objetivo 5 visa combater a desigualdade de gênero em nível mundial e promover ações de empoderamento feminino, sendo que uma das metas é eliminar todas as formas de violência contra as mulheres e meninas nas esferas públicas e privadas.

A urgência em se trabalhar o tema deu-se também pelo fato de Itajaí ter sido a cidade de Santa Catarina que mais registrou denúncias de violência contra a mulher em 2017. Segundo dados da Polícia Militar, foram mais de 800 casos registrados até agosto daquele ano, o que demonstra a importância de se trabalhar essas questões em diversas esferas. Dentro deste contexto, entende-se que é importante abordar o assunto em sala de aula até para que a escola não seja mais um desses espaços em que se legitima a desigualdade de gênero.

Além dos dados da Polícia Militar, no próprio câmpus Itajaí do IFSC é possível observar a importância de se trabalhar o tema. Resultados preliminares da pesquisa "Gênero na escola e no mundo do trabalho", desenvolvida no câmpus Itajaí, mostram discriminações e desigualdades de gênero sofridas por alunas do curso técnico em Mecânica e enfatizam a necessidade de trazer esse tema para ser discutido dentro da escola.

Observa-se também a necessidade de incorporação da temática de gênero no currículo. A ONU Mulheres no mundo e no Brasil tem investido em ações inovadoras de prevenção da violência de gênero nas áreas de arte, cultura, educação, esportes, tecnologias da informação e comunicação. Uma delas é a iniciativa "0 valente não é violento", da campanha "Una-se pelo fim da violência contra as mulheres". Ela tem como objetivo estimular a mudança de atitudes e comportamentos dos homens, enfatizando a responsabilidade que devem assumir na eliminação da violência contra as mulheres. Esta proposta convida as pessoas a repensar e transformar os estereótipos dos papéis sociais denominados femininos ou masculinos e das crenças sobre 0 que as mulheres e os homens devem ser ou fazer, que são a base arraigada culturalmente da desigualdade de gênero, da discriminação das mulheres e, consequentemente, da violência 
exercida contra elas. Um dos materiais produzidos pela iniciativa "0 valente não é violento", por exemplo, é uma proposta de currículo educativo sobre promoção de igualdade de gênero entre adolescentes e jovens brasileiros. Essa proposta está centrada em três eixos: normas sociais e de gênero, direitos sexuais e reprodutivos, violências baseadas em gênero (NASCIMENTO; ARRUDA, 2014).

Apesar da importância e urgência social desse tema, revisões de currículos educativos de alguns estados no Brasil demonstram que a igualdade de gênero e étnico-racial, as sexualidades e 0 enfrentamento das violências não são temas priorizados no currículo. 0 contexto apresenta avanços nas políticas públicas brasileiras envolvendo esta temática como a Lei Maria da Penha, referência no combate à violência. No entanto, este tema de fundamental importância em nível mundial tem sido cada vez mais alvo de iniciativas de retrocessos atuais como a extinção do "Ministério das Mulheres, da Igualdade Racial, da Juventude e dos Direitos Humanos", ataques de grupos e projetos de lei como o "Escola sem partido", e a retirada dos termos "gênero" e "orientação sexual" da Base Nacional Curricular Comum (BNCC).

Educadores, pesquisadores e grupos ligados a movimentos sociais defendem a necessidade desse tema fazer parte do currículo na escola e no debate da sociedade em espaços não formais de educação, uma vez que a realidade em sala de aula mostra a urgência e a contemporaneidade de se abordar esse tema. Há inclusive, por parte da secretaria municipal de educação de Itajaí, uma demanda para que sejam ofertados cursos de formação para professores e orientadores educacionais sobre como abordar esses temas em sala de aula. Isto reforça a necessidade da formação continuada de professores da rede pública, em especial de forma gratuita e na região do Vale do Itajaí, podendo contribuir para que a sala de aula seja de fato inclusiva do ponto de vista da diversidade (uma vez que esta formação não faz parte da maioria dos currículos escolares), conforme Nota Técnica n. 24/2015 CGDH/DPEDHUC/SECADI/MEC. 0 contexto revela, portanto, a importância de se promover o letramento crítico para este tema, de forma que os alunos e professores possam se tornar "leitores do mundo", compreendo-0 a partir de uma perspectiva crítica e objetivando a justiça social.

\section{Objetivos e metodologia}

0 projeto teve como objetivo geral promover reflexões sobre questões de gênero e incentivar a formação de leitores críticos em escolas da EJA da rede pública de Itajaí. Para atingir isso, estabeleceu-se os seguintes objetivos específicos: (a) incentivar a leitura crítica entre alunos e professores por meio da leitura dramática de contos da obra Olhos D’Água; (b) promover a reflexão acerca de questões relacionadas a gênero na sociedade e, mais especificamente, na escola; (c) ampliar 0 acervo de livros da biblioteca do câmpus e das escolas envolvidas no projeto; (d) possibilitar aos alunos e alunas do câmpus Itajaí e de outras escolas públicas do município uma atividade de extensão, ensino e pesquisa sobre gênero e leitura crítica; e, (e) incentivar e formar leitores para a criação, em 2018, de um clube de leitura, na cidade de Itajaí, de obras literárias escritas por mulheres.

0 público atendido pelo projeto envolveu estudantes e professores de escolas da EJA do município de Itajaí, por meio da Secretaria Municipal de Educação. Contou-se com a participação das seguintes escolas: Centro Educacional Pedro Rizzi, Escola Básica Gaspar da Costa Moraes, Escola Básica Professora Thereza Bezerra de Athayde, Escola Básica Aníbal Cezar, Escola Básica João Duarte, Escola Básica Professora Judith Duarte de Oliveira e Centro Educacional de Cordeiros. A metodologia consistiu em promover oficinas de formação sobre leitura dramática para professores, roda de conversa sobre questões de gênero e promoção de leituras dramáticas públicas nas escolas participantes. Para incentivar a leitura crítica dos professores, foi ofertada, inicialmente, uma oficina de formação com o professor Samuel Ivan Kuhn, do câmpus Joinville do IFSC, para a leitura dramática. A oficina foi dividida em dois encontros de três horas. Após essas oficinas, foi realizada com os professores uma roda de conversa abordando questões de gênero. A partir destas duas primeiras atividades, os professores participantes, em parceria com os membros deste projeto, promoveram em diferentes leituras dramáticas de contos do livro Olhos D’Água. 


\section{Resultados e discussão}

0 projeto foi executado no período de outubro a dezembro de 2017. Foram realizadas pela equipe executora as seguintes atividades: encontros semanais de planejamento; dois encontros de oficina de formação para professores sobre leitura dramática, com duração total de 6 horas, conduzidos pelo professor Samuel Kuhn (câmpus Joinville do IFSC) no Centro Educacional Pedro Rizzi; roda de conversa com os professores participantes do projeto para leitura e discussão do texto "Representações de Gênero e Afrodescendência na Obra de Conceição Evaristo", de Francineide Santos Palmeira e Florentina da Silva Souza, e roda de conversa com professores participantes sobre relações de gênero e sobre a vida e obra da escritora Conceição Evaristo; três encontros envolvendo professores e alunos em escolas da rede pública de Itajaí que ofertam EJA (Escola Básica Aníbal Cesar, Escola Básica João Duarte, Escola Básica Professora Thereza Bezerra de Athayde) para realização de leitura e discussão de contos do livro Olhos D'Água. Esses encontros, realizados nas escolas, foram mediados pelos professores participantes do projeto e tinham como público-alvo os próprios alunos da EJA. Nesta etapa, a equipe executora atuou como facilitadora das atividades, já que os professores participantes do projeto propuseram diferentes atividades para seus alunos de forma a replicar ou iniciar as discussões a partir dos aprendizados que tiveram durante as oficinas e rodas de conversa. Desta forma, alguns professores optaram por realizar uma leitura dramática de um conto da escritora Conceição Evaristo promovendo uma discussão em forma de roda de conversa, enquanto outros fizeram a leitura dramática de um conto da autora omitindo o final e propiciando que os alunos criassem o seu próprio desfecho para a história. Já alguns professores solicitaram que os alunos escrevessem cartas para a escritora sobre suas impressões acerca da obra.

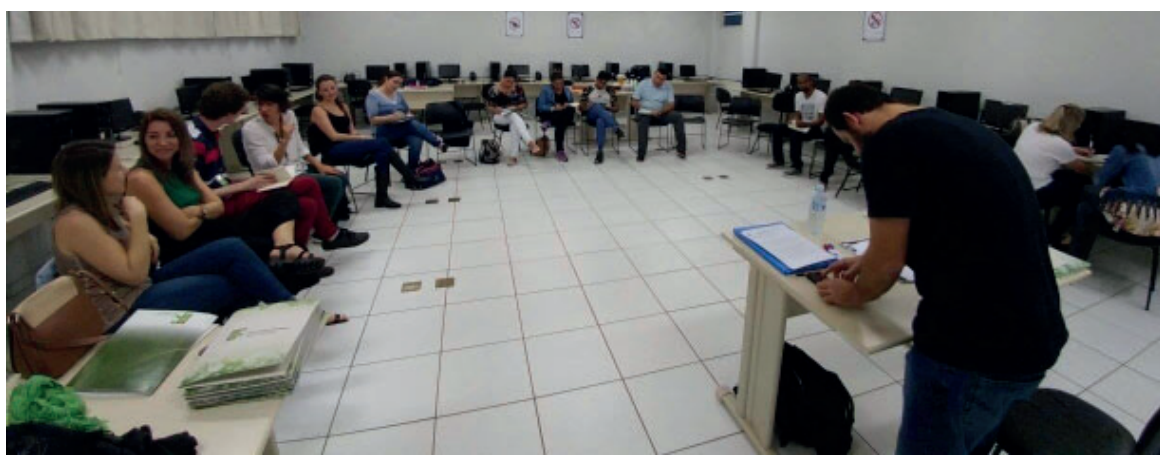

Imagem 1: Oficina de leitura dramática com professores do EJA Fonte: Juliana Wilhelm

Como resultados qualitativos, pode-se apontar, primeiramente, o incentivo ao desenvolvimento da leitura crítica e ampliação do repertório de livros de autoria feminina entre alunos e professores a partir de atividades de ensino, pesquisa e extensão. Todas as escolas participantes, bem como a biblioteca municipal de Itajaí receberam exemplares da obra, livros estes que foram comprados com os recursos disponíveis para o projeto de extensão, contribuindo assim para a ampliação do acervo dessas bibliotecas.

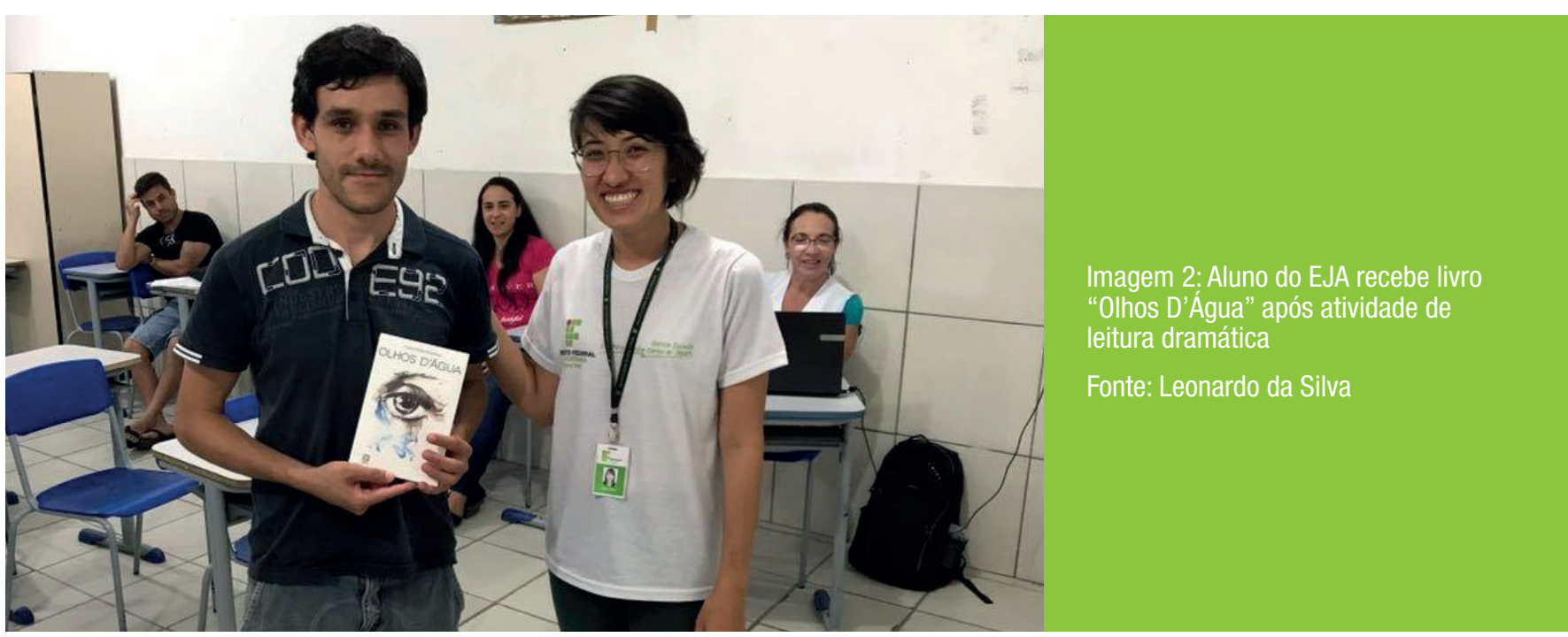


Observou-se que, de maneira geral, os participantes - alunos e professores do EJA - não conheciam a escritora do livro Olhos D'Água e que, a partir das atividades realizadas durante o projeto, muitos demonstraram interesse em conhecer melhor seu trabalho bem como suas obras. Muitos alunos se identificaram com a autora pelo fato de ela ser negra, de origem pobre e por ter concluído seus estudos de forma tardia.

Imagem 3: Alunos do EJA socializam suas produções a partir de conto do livro "Olhos D'Água"

Fonte: Leonardo da Silva

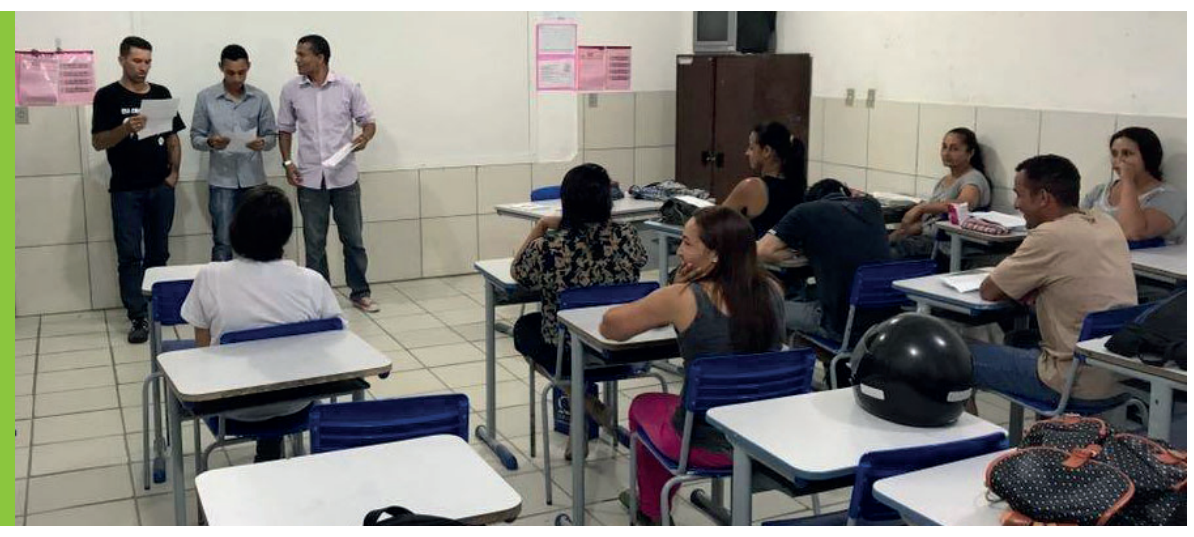

0 projeto contribuiu para a formação dos professores sobre leitura dramática, uma vez que eles refletiram sobre 0 uso da leitura em sala de aula como uma forma de provocar a reflexão e 0 aprendizado a partir do diálogo, e apresentou formas de se trabalhar questões de gênero na escola. Ao colocar o tema em debate, contribui-se para que alunos e professores pensem em ações que promovam a igualdade de gênero.

Por fim, o projeto serviu como divulgação do IFSC na rede pública de educação do município em que há um público em potencial para os cursos técnicos da instituição. Muitos desses alunos da EJA não conheciam a instituição; tampouco sabiam que ela era uma escola pública.

Quanto aos resultados quantitativos, oportunizou-se um curso de formação sobre leitura dramática bem como a discussão sobre relações de gênero para 16 professores da rede pública da EJA do município de Itajaí. Cinco destes professores fizeram atividades nas escolas com a participação de aproximadamente 110 alunos. Além disso, foram adquiridos, com o recurso financeiro do projeto, 30 exemplares do livro "Olhos D'Água" doados às bibliotecas das escolas da EJA, à biblioteca pública do município e à biblioteca do IFSC Câmpus Itajaí e três exemplares do livro "Outros jeitos de usar a boca", de Rupi Kaur, doados à biblioteca do câmpus Itajaí, cuja temática está relacionada com as discussões do projeto. É importante ressaltar que o projeto foi desenvolvido e implementado através de uma parceria com o Programa de Diversidade Étnicoracial de Gênero e Combate ao Bullying da Secretaria de Educação de Itajaí, que apresentou a demanda da formação de professores acerca de questões de gênero, bem como possibilitou a condução das atividades junto às escolas.

\section{Considerações finais}

0 projeto, embora de curta duração, serviu como propulsor de reflexão sobre questões de gênero e de incentivo à leitura não somente entre os professores da Educação de Jovens e Adultos, mas, principalmente, entre os alunos das escolas participantes. Dessa forma, a terceira etapa do projeto, em que os professores atuaram como replicadores do projeto ao propor diferentes atividades envolvendo a leitura dramática de contos do livro "Olhos D'Água", foi de fundamental importância para concretizar os objetivos delineados. Isso ressalta a importância de trabalhar com a temática de gênero de diferentes formas e em todo o currículo, uma vez que se trata de um assunto complexo e de importante relevância para o contexto de vida dos alunos.

Também é importante ressaltar que, dentre as dificuldades encontradas para a realização do projeto, estiveram o pouco envolvimento dos participantes, neste caso os professores da EJA, na formação sobre leitura dramática bem como a não compreensão da importância de se levar as questões discutidas no decorrer do projeto para 0 contexto escolar. Alguns participantes desistiram durante o projeto e outros não quiseram realizar atividades nas escolas envolvendo 
os alunos da EJA devido à proximidade do término do semestre letivo. É importante, nesse sentido, destacar que a questão da igualdade de gênero seja entendida como transdisciplinar, uma vez que não deve se restringir a uma unidade curricular específica, e que deve ser incluída na formação docente inicial e continuada, de forma a capacitar os professores a tornarem a escola (e, por consequência, a sociedade) um espaço mais igualitário.

\section{Referências}

BRASIL. Ministério da Educação. Base Nacional Comum Curricular - Documento preliminar. Brasília, DF, 2015.

BRASIL. Ministério da Educação. Nota Técnica n. 24/2015 -CGDH/DPEDHUC/SECADI/ MEC. Brasília, DF, 2015. Disponível em: <http://www.spm.gov.br/assuntos/conselho/notatecnica-no-24-conceito-genero-no-pne-mec.pdf>. Acesso em: 21 fev. 2018.

CROOKES, G. V. Critical ELT in action: foundations, promises, praxis. New York: Routledge, 2013.

DALCASTAGNÈ, Regina. Literatura brasileira contemporânea: um território contestado. Vinhedo: Horizonte, 2012.

EVARISTO, Conceição. Olhos D’Água. Rio de Janeiro: Pallas, 2017.

KAUR, Rupi. Outros jeitos de usar a boca. São Paulo: Planeta, 2017.

LIMA, Marcos Hidemi. "Olhos d'água”, de Conceição Evaristo, aborda a violência e a miséria que marcam a vida de muitos afro-brasileiros. Jornal Rascunho, Curitiba, n. 188, fev. 2016. Disponível em: <http://rascunho.com.br/23903-2/>. Acesso em: 21 fev. 2018.

LOURO, Guacira. Gênero, sexualidade e educação: uma perspectiva pós-estruturalista. Petrópolis: Vozes, 2008.

NAÇ̃̃ES UNIDAS NO BRASIL. Transformando nosso mundo: a agenda 2030 para 0 desenvolvimento sustentável. Rio de Janeiro, 2015. Disponível em: <https://nacoesunidas.org/ wp-content/uploads/2015/10/agenda2030-pt-br.pdf>. Acesso em: 21 fev. 2018.

NASCIMENTO, Marcos; ARRUDA, Silvani. Valente não é violento: campanha do secretáriogeral das Nações Unidas pelo fim da violência contra as mulheres. Brasília: ONU Mulheres, União Europeia, nov. 2014.

OLIVEIRA, Eliana Kefalás. Leitura, voz e performance no ensino de literatura. Signótica, Goiânia, v. 22, n. 2, p. 277-307, jul/dez, 2010. Disponível em: <https://www.revistas.ufg.br/ sig/article/view/13609/8736>. Acesso em: 21 fev. 2018.

PALMEIRA, F. S.; SOUZA, F.S. Representações de Gênero e Afrodescendência na obra de Conceição Evaristo. In: ENCONTRO DE ESTUDOS MULTIDISCIPLINARES EM CULTURA, 4., 2008. Salvador. Anais eletrônicos... Salvador: UFBA, 2008. Disponível em: <http://www. cult.ufba.br/enecult2008/14440.pdf>. Acesso em: 21 fev. 2018.

PUPO, Katia. Questão de gênero na escola. Escola sem homofobia, São Paulo, v. 1, p. 1-23, out./jul. 2007. 